\title{
THE EFFECT OF BODY POSITION CHANGE ON LUNG COMPLIANCE IN NORMAL SUBJECTS AND IN PATIENTS WITH CONGESTIVE HEART FAILURE*
}

\author{
By JOHN TURNER SHARP $†$ WITH THE TECHNICAL ASSISTANCE OF \\ DANIEL RAKOWSKI $\ddagger$ AND DIANE KEEFER \\ (From the Department of Medicine of the University of Buffalo School of Medicine and the \\ Buffalo General Hospital, Buffalo, N. Y.)
}

(Submitted for publication October 6, 1958; accepted November 25, 1958)

Since the work of Christie and Meakins (1), the lungs of patients with heart failure have been acknowledged to resist inflation to a greater extent than normal lungs. More recent studies of pulmonary mechanics in patients with congestive heart failure (2-5) have emphasized the lowered lung compliance as well as moderate increases in pulmonary resistance. That acute changes in lung compliance can occur in man has been shown by Saxton, Rabinowitz, Dexter and Haynes (6) who demonstrated acute decreases in lung compliance on exercise in patients with heart disease associated with increases in pulmonary artery wedge pressure, and by Bondurant, Hickam and Isley (7) who demonstrated acutely decreased compliance in normal subjects when transient pulmonary congestion was induced by sudden inflation of a pressurized suit. Because of the importance of body position in cardiac dyspnea, a feature of which is orthopnea, the present study was undertaken to determine what, if any, changes in the static volume-pressure characteristics of the lungs occurred in normal subjects and in orthopneic patients with heart failure on changing from the sitting to the horizontal (prone) body position.

\section{METHODS}

The data herein presented were derived from simultaneous oscillographic recordings 1 of transpulmonary pressure, air flow and the tidal volume. Esophageal pressure was recorded by means of a balloon catheter (balloon length, $15 \mathrm{~cm}$.) similar to that described by Mead,

* Supported by grants from the American Heart Association.

$\dagger$ Established Investigator of the American Heart Association and Buswell Fellow in Medicine.

$\$$ Supported by a grant from the Heart Association of Erie County.

${ }^{1}$ Recorder manufactured by Electronics for Medicine Incorporated, White Plains, N. Y.
McIlroy, Selverstone and Kriete (8). It was inflated with $1 \mathrm{ml}$. of air when in use. This catheter was attached to one side of a differential pressure transducer ${ }^{2}$ of low volume displacement with small and equal air volumes on the two sides of the diaphragm. The other side of the transducer was connected to the mouthpiece so that the pressure recorded represents the difference between pressures in the mouth and the esophagus or the transpulmonary pressure. The 95 per cent response time of this system was approximately 0.005 second and its natural frequency, 100 cycles per second. Airflow was recorded by measuring the differential pressure across a 400 -mesh monel metal screen two inches in diameter by means of a differential pressure transducer ${ }^{3}$ also provided with small and equal volumes on either side of the diaphragm. The 95 per cent response time of the flow recording system was 0.015 second and its natural frequency, 40 cycles per second. Tidal volume was recorded in early experiments on a 7 L. spirometer. 4 To the spirometer counterweight was attached an electrical contact to a resistance wire which formed two arms of a resistance bridge activated by a mercury cell; the output of this bridge was fed into a DC amplifier. The output of this volume transducer was linearly related to volume. In later experiments a low resistance, low inertia Krogh spirometer ${ }^{5}$ was used, at the fulcrum of which was attached an angular displacement transducer, ${ }^{6}$ the output of which was also linearly related to volume. Airflow was interrupted by a specially constructed rotary interrupter valve. ${ }^{7}$ The rate of interruption was five interruptions per second with equal "on" and "off" times of 0.1 second. The transition time between flow and interruption was onesixth of the half-cycle time. Figure 1 is a recording of transpulmonary pressure, tidal volume and airflow illustrating the general form of the tracings from which data were derived and showing the "square wave" characteristics at interruption in the upper pressure curve. It is seen that airflow falls substantially to zero during

2 The Sanborn Company 267B pressure transducer.

${ }^{3}$ Built by Mr. Frederick E. Wiedeman, Department of Physiology, Harvard University School of Public Health. 4 The Collins Company respirometer.

5 Fred J. Christensen, Watertown, Mass.

${ }^{6}$ Minneapolis Honeywell microsyn position indicator.

7 Adapted from a design originated by Dr. John A. Clements. 


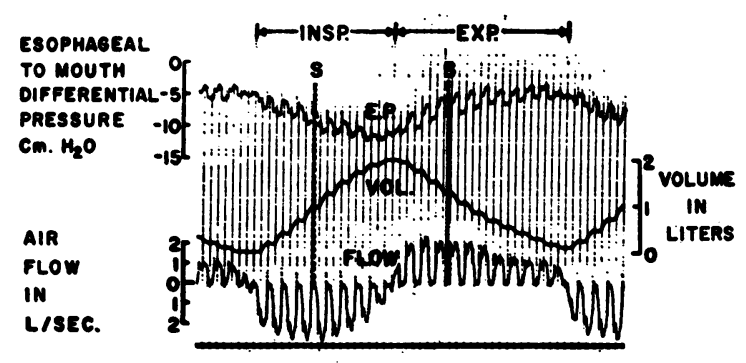

Fig. 1. Oscillographic Tracing of TranspulmoNary Pressure, Tidal Volume and Airflow in NorMAL SUBJECT 4

Time lines are 0.1 second; vertical dashed lines labeled $\mathrm{S}$ indicate points at which airflow is interrupted or static points. Static volume-pressure curves are obtained by plotting static pressure points against static volume points (the level steps in the middle tracing).

the static (interrupted) phase. Rapid interruption as described was used in this study because it was better tolerated by breathless subjects and enabled an entire volume-pressure curve of many points to be taken during one breath, shortening the time and effort necessary to obtain volume-pressure data.

Though true static pressure equilibration was prob-

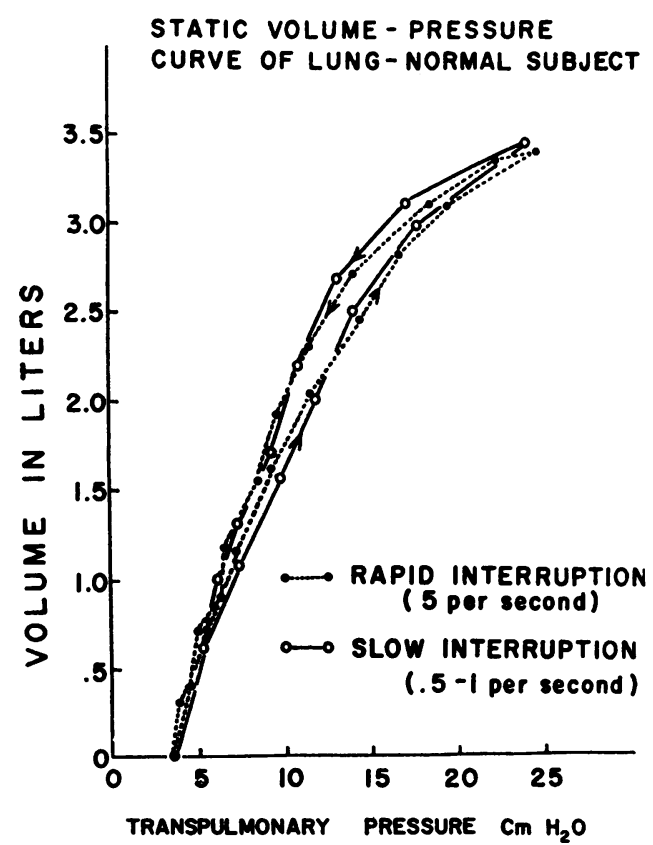

Fig. 2. Static Volume-Pressure Curves on a Normal Subject Done at Two Rates of Interruption AS INDICATED

Dashed lines with solid points indicate interruption at five per second; solid lines with open points indicate flow interruption voluntarily performed by the subject onehalf to one time per second. The two curves are hardly distinguishable. ably not attained throughout the lung at this rapid rate of interruption, conditions closely approaching static equilibrium were obtained, certainly in normal subjects and probably in patients with heart failure, as evidenced by the observations shown in Figures 2 and 3 that the volume-pressure curves obtained by interruption at five interruptions per second closely resembled those obtained during slower interruptions. The rate at which static equilibration is approached is affected by the magnitude of airway resistance. Unpublished observations made by Clements and associates (9) and the author indicate that equilibration should be virtually complete at this rate of interruption up to resistance values of $10 \mathrm{~cm} . \mathrm{H}_{2} \mathrm{O}$ per L. per second. In none of the patients was this resistance value exceeded (Table I).

On each of eight healthy young normal subjects and in seven of the eight patients with congestive failure, volume-pressure data were collected in the sitting position and immediately after changing to the prone position. Lung compliance, expressed in $\mathrm{L}$. per $\mathrm{cm} . \mathrm{H}_{2} \mathrm{O}$, was taken as the slope of the static volume-pressure curve between the resting end-expiratory volume and $1 \mathrm{~L}$. above this volume. Each compliance value is an average from 10 breaths. Because of observations that lung compliance varies depending on the size of preceeding breaths (10), volume-pressure measurements were made only on maximal breaths encompassing the entire inspiratory capacity (from resting end-expiratory volume to full lung capacity). As it is known that compliance changes with frequency in the presence of unequal time constants of ventilated units (11), the frequency of interruption was kept the same (five per second in all studies) and an effort was made to record all volume-pressure data at the same breathing frequency in each subject. Tidal volume and frequency data are included with compliance values

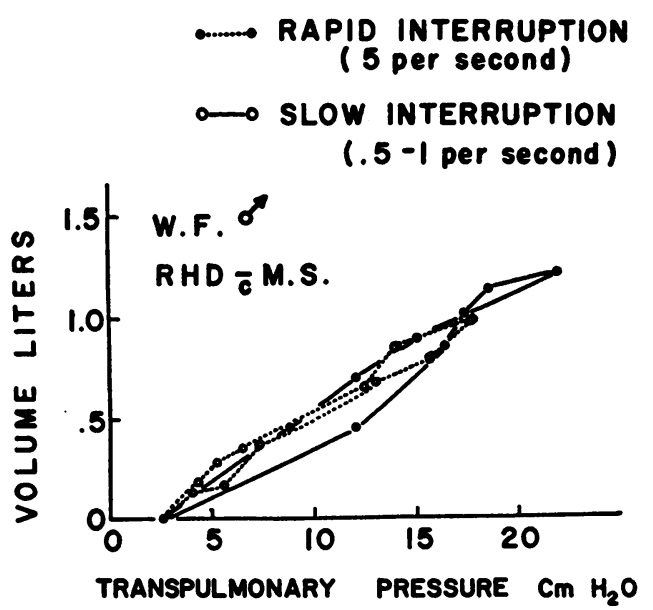

Fig. 3. Static Volume-Pressure Curves on Patient 2 Done at Two Rates of Interruption

Open points with dashed lines, rapid interruption at five per second; solid points with solid lines, slow interruption voluntarily performed by the patient. The two curves yield essentially the same compliance. 
TABLE I

Changes in lung compliance with body position change

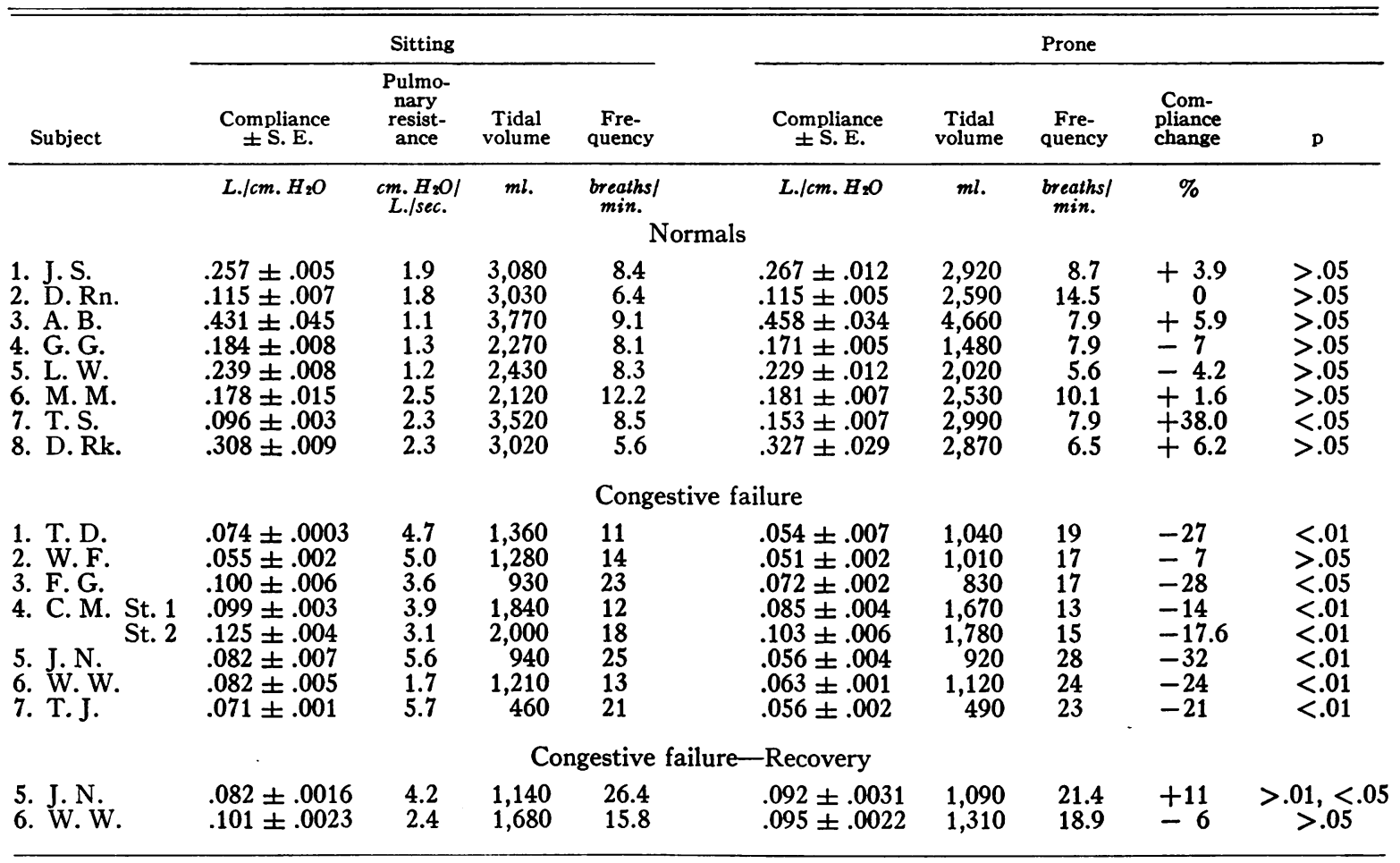

in Table 1. In all patients the catheter was taped tightly to the nose and face to keep the esophageal balloon catheter in the same location throughout the study. Pulmonary resistance was calculated from uninterrupted breaths by the method of von Neergaard and Wirz (12). Values shown are averages from five breaths and were calculated at points where the air flow rate was $1 \mathrm{~L}$. per second.

Observations made by Knowles, Hong and Rahn (13) suggesting deviation of esophageal pressure from pleural pressure below resting end-expiratory volume prompted the authors to make all volume-pressure measurements above the resting end-expiratory volume. This, however, shifted with body position both in normal subjects and in patients. These shifts in volume are summarized below. Observations by Pryor, Hickam, Sieker and Page (14) and by Knowles, Hong and Rahn (13) suggest that an artifact in esophageal pressure is produced by the weight of heart and mediastinum upon the balloon catheter in the supine body position. This artifact was absent in the prone position. For this reason the supine position [used, incidently, by Marshall, McIlroy and Christie (4) in their study of several orthopneic patients] was avoided, and subjects were studied in only the prone and sitting positions. In two patients and two normal subjects compliance was studied repeatedly while resting in the supine position over a period of four hours. In these studies it was assumed that the esophageal pressure artifact would remain relatively constant and that therefore compliance changes occurring over a period of time represented changes in the properties of the lungs. In justification of this assumption were the observations that: 1) No significant compliance changes were found in two normal subjects after four hours in the supine position, and 2) no significant compliance changes were found in the two cardiac patients after successful treatment of their congestive failure though significant changes had occurred when these patients had first been studied prior to treatment.

In the studies of the acute effect of position change, volume-pressure measurements were made in the sitting position and within one to five minutes after changing to the prone position (as soon after the change as satisfactory measurements could be made). The eight normal subjects were all young male physicians or laboratory personnel without history or physical evidence of lung or heart disease. Of the eight patients with heart disease, four had rheumatic heart disease with predominant mitral valve involvement, and four had arteriosclerotic heart disease. At the time of study all patients had exertional dyspnea, orthopnea and crepitant rales confined to the bases of one or both lungs. It is recognized that the distinction between pulmonary edema of mild degree and "pulmonary congestion" is an arbitrary and purely clinical one. Right ventricular failure was also present in all with peripheral edema and elevated systemic venous pressure. A brief summary of each patient is presented in an appendix. In two patients four-hour supine 
studies were done while in failure and repeated following successful treatment of failure; in one of these (Case 8, D.C.) no study of the acute sitting to prone compliance change was made. In two patients, studies of acute changes in compliance between sitting and prone positions were also repeated following recovery (Figure 4 and bottom of Table I).

\section{RESULTS}

\section{Acute compliance changes in position change}

Lung compliance did not change significantly in seven of the eight normal subjects studied (Table I) on changing from sitting to prone. In the normal subject in whom a significant change was seen, the compliance unaccountably rose by 38 per cent. In six of seven patients in whom the acute changes in compliance were studied on changing from sitting to prone, significant decreases in compliance were found. In the remaining patient compliance fell by 7 per cent, a decrease not statistically significant at the 5 per cent level. Case 4 was clinically in about the same degree of failure when studied on two occasions eight

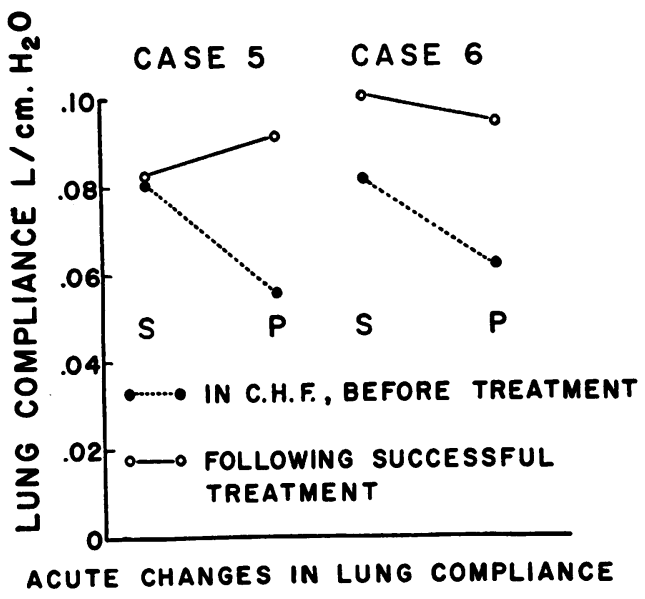

Fig. 4. Acute Changes in Lung Compliance which Occurred on Change from the Sitting to the Prone Position in Two Patients with Congestive Heart FAILURE

Solid points with dashed lines indicate change in compliance which occurred on changing from sitting to prone position prior to treatment; open points with solid line indicate change in lung compliance which occurred on position change following recovery from failure. In both cases the compliance decrease occurring while in failure was significant at the 1 per cent level. Following recovery a slight rise, significant at the 5 per cent level, was seen in Case 5 and in Case 6 a slight fall was seen which was not significant at the 5 per cent level. months apart. Compliance changes of similar magnitude were observed on these two occasions. The average fall in compliance in the patients with heart failure was 21.9 per cent. In Patients 5 and 6 the study of acute compliance changes was repeated after successful treatment of their failure two weeks and six months, respectively, after the first study. Whereas in the first study significant decreases in compliance $(-32$ and -24 per cent) were found, in the second study compliance did not change significantly in one and showed a slight but significant rise in the other from the sitting to the prone position (Figure 4). Of significance also is the observation that compliance returned to the sitting value in the five patients in whom measurements in the sitting position were repeated immediately after the prone determinations.

\section{Volume changes}

In four of the normal subjects and four of the patients with heart failure, the vital capacity was measured with relation to the resting end-expiratory position in sitting and prone positions. In the four normal subjects vital capacity was $4.8 \mathrm{~L}$. sitting and $4.4 \mathrm{~L}$. in the prone position. Vital capacity consistently fell in changing from the sitting to the prone position, the change varying from 5.7 to 13.6 per cent and averaging 9.6 per cent. In the patients with congestive heart failure vital capacity averaged $2.04 \mathrm{~L}$. sitting and 1.84 L. prone. In these patients the vital capacity also fell consistently in changing from the sitting to the prone position, the average change being 11 per cent with values ranging from minus 4 per cent to minus 16 per cent. In changing from sitting to prone the resting end-expiratory volume within the lungs fell, resulting in a decrease in the expiratory reserve volume. In the normal subjects, the decrease averaged 31 per cent. The decrease in expiratory reserve volume in the patients with heart failure ranged from 5 to 42 per cent with an average of 24 per cent. These changes in resting end-expiratory position were not measured directly but are inferred from changes in the expiratory reserve volume (ERV). Attempts were made to determine the shift in resting end-expiratory position directly by recording tidal volume continuously for several minutes 

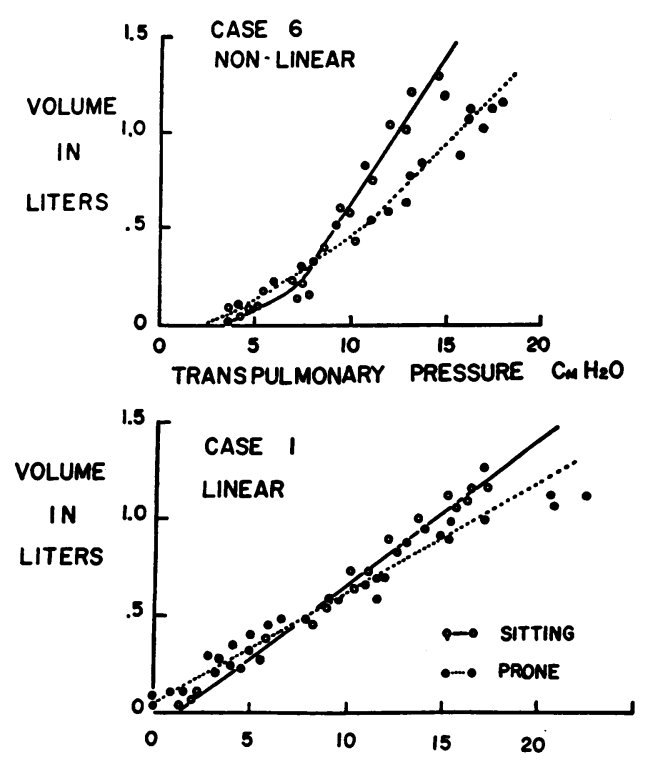

TRANSPULMONARY PRESSURE $\mathrm{C}_{\mathrm{MH}} \mathrm{H}_{2} \mathrm{O}$

Fig. 5. Inspiratory Volume-Pressure Curves in Cases 6 and 1 Showing Examples of Nonlinear and Linear Inspiratory Volume-Pressure CuRves

The solid lines indicate the volume-pressure curves obtained in the sitting position; the dashed lines indicate the volume-pressure curves obtained in the prone position in each case.

before, during and after the position change. However, alterations in breathing pattern and in gas exchange coincident with the position change made this shift difficult to determine with accuracy. Much greater variation occurred upon repetition of these direct determinations than occurred among repeated indirect determinations obtained by subtracting the prone ERV from the sitting ERV.

Aside from the striking differences in vital capacity between the normal subjects and the patients with heart failure there were no significant differences in the volume data between the two groups when expressed on a percentage basis. There was no correlation between compliance change and volume change in either normal or heart failure groups in going from the sitting to the prone position.

\section{Shape of volume-pressure curves}

The inspiratory limbs of the lung volume-pressure curves were linear in Cases 1, 2, 4 and 7 and also in Case 8 , in whom only supine studies were done. Cases 3, 5 and 6 showed nonlinear inspiratory volume-pressure curves with a flatter slope (lower compliance) at smaller lung volumes and steeper slope (higher compliance) as the lung expanded. Figure 5 illustrates typical linear and nonlinear inspiratory volume-pressure curves with the change occurring on shifting from the sitting to the prone position. It should be noted that merely shifting the resting end-expiratory position (volume) without any change in the slope of the volume-pressure curve could alone cause a fall in compliance in those cases where the volume-pressure curve was nonlinear. It is also of interest that in Case 5, the volume-pressure curve was nonlinear when the patient was first studied (in heart failure) but was linear two weeks later when the patient was restudied after successful treatment.

"Static" lung hysteresis was noted in most of the patients with heart failure and for comparablysized breaths was greater than normal (15). It decreased but still remained greater than normal on recovery from heart failure. Figure $6 \mathrm{com}$ pares static volume-pressure curves showing hysteresis from Case 6 before and after treatment. A volume-pressure curve from a normal subject with the usual minimal degree of hysteresis is shown for comparison. Volume-pressure hysteresis was not appreciably different in the sitting and prone positions.

"STATIC"LUNG HYSTERESIS

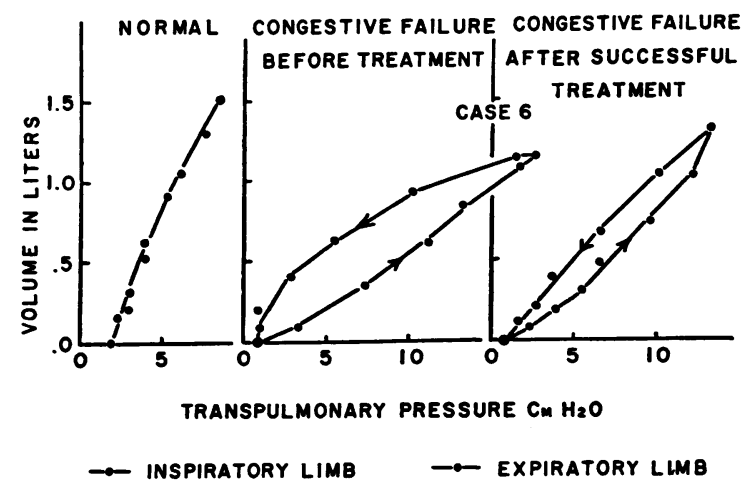

Fig. 6. "Static" Lung Volume-Pressure Curves Made on Breaths of Comparable Size on a Normal Subject and on a Patient with Congestive Failure Before and After Successful Treatment

The hysteresis "loop" is well shown; it is seen to be least in the normal subject and greatest in the patient with congestive failure prior to treatment. 


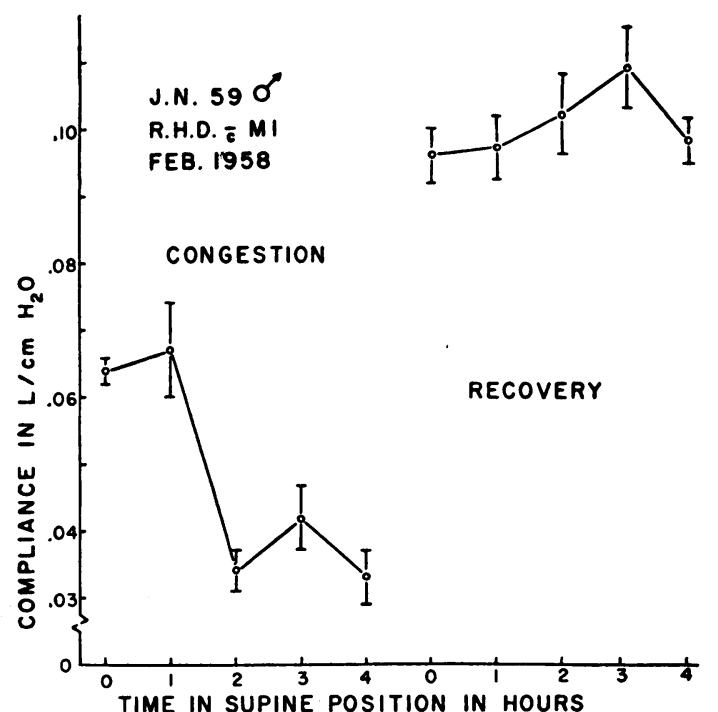

Fig. 7. Compliance Change in Patient 5 Occurring over Two Four Hour Periods of Observation in the Supine Position

The second (recovery) study was done three weeks after the first. At the time of the first set of observations (labeled "congestion") the patient was in frank cardiac failure with edema and systemic venous hypertension. At the time of the repeat study (labeled "recovery") venous pressure was normal, edema was absent and patient had lost 45 pounds. The vertical brackets about each point indicate plus or minus two standard errors.

\section{Prolonged studies in the supine position}

In Patients 5 and 8 compliance was repeatedly measured while they rested in the supine position. Significant decreases in lung compliance were noted over four hour periods in both patients. These changes are shown in Figures 7 and 8. In spite of the considerable changes in compliance neither subject complained of increased breathlessness except when rebreathing from the spirometer, and there were no changes in physical findings over the chest to suggest the occurrence of clinical pulmonary edema. These two patients were restudied, Subject 5 three weeks after his first study, and Subject 8 one week after the initial study, on which occasions both patients were free of edema and systemic venous hypertension. The righthand portions of Figures 7 and 8 labeled "recovery" show that no significant changes occurred during the repeat studies. Repeated measurements of compliance in two normal subjects over periods of four hours in the supine position showed no significant changes.

\section{DISCUSSION}

The acute decrease in lung compliance in cardiacs upon assumption of the prone position were of moderate degree ranging from 7 to 31.8 per cent. The absence of this change in normal subjects and its disappearance in the two patients restudied after successful treatment indicate that the changes are associated with the congested state and not due to an artifact of esophageal pressure registration as is known to occur in a supine position. The rapidity of this compliance fall (within one to five minutes) coupled with the observation made in five patients that the compliance fall was rapidly reversible argue against the change being due to pulmonary edema. Borst and co-workers (16) found in open-chest dog preparations that increases in pulmonary blood flow and pulmonary artery pressure produced no change in compliance so long as left atrial pressure (and inferentially pulmonary capillary pressure) remained normal. Acute and reversible decreases in compliance of 20 to 30 per cent were seen when left atrial pressure was elevated from normal levels $\left(0\right.$ to $10 \mathrm{~cm} . \mathrm{H}_{2} \mathrm{O}$ ) to 50 to $60 \mathrm{~cm}$. $\mathrm{H}_{2} \mathrm{O}$. From their data the relationship between compliance and left atrial pressure, though inverse, appeared linear. The conclusion that pulmonary capillary pressure, probably because of its rela-

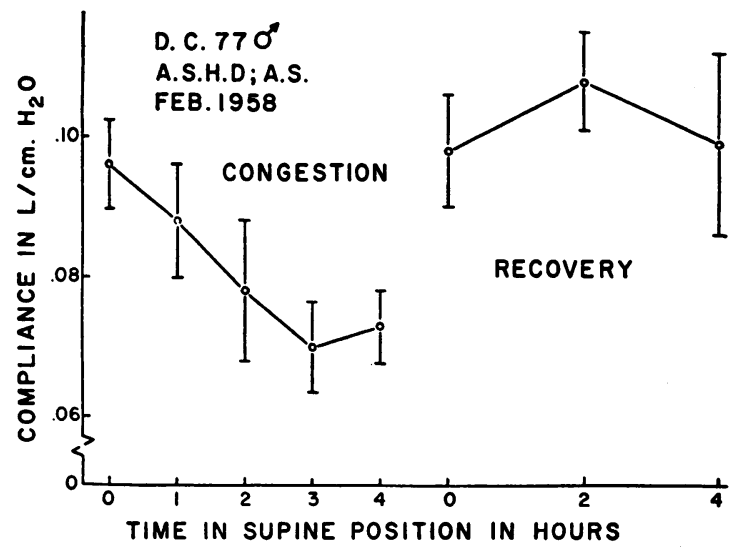

Fig. 8. Compliance Change in Patient 8 Occurring over Two Four Hour Periods of Observation in the Supine Position

The second study was done one week after the first. When first studied (data shown under "congestion"), venous pressure was elevated and edema present. When restudied one week later he had lost 30 pounds, had normal venous pressure and no edema. The vertical brackets indicate plus or minus two standard errors. 
tionship to pulmonary vascular volume, is an important determinant of lung compliance seems justified and worthy of emphasis.

It has been found in normal subjects by Sjöstrand (17) using plethysmographic techniques that an average of $640 \mathrm{ml}$. of fluid shifts from the lower portions of the body to the thorax on change from the erect to the recumbent position. Three-quarters of this volume was estimated to enter the lungs. Lägerlö, Eliasch, Werkö and Berglund (18) found in one normal subject and one hypertensive patient that pulmonary capillary pressure and central blood volume rose on change from the upright to the horizontal position. Neither of these patients was in congestive heart failure, however. The lack of analogous data from patients with heart failure allows little more than speculation as to whether greater than normal increases in these variables occur in cardiacs in failure on assuming the horizontal position. Suggestive data on this point have however been provided by Donald, Bishop, Cumming and Wade (19). These investigators, studying the effects of position change in normals and cardiacs, found that pulmonary artery pressure rose to a greater extent in cardiacs than in normals in assuming the recumbent position. It was not determined whether this rise in pulmonary artery pressure was associated with a rise in pulmonary vascular resistance or with a rise in pulmonary capillary pressure.

The observations of increased pulmonary vascular volume and capillary pressure in normal subjects together with the observation that vital capacity decreases slightly on assuming the recumbent position (20) (a decrease, incidently, prevented by venous occlusion cuffs on the extremities) suggest that compliance should be slightly lower in normals in the recumbent position. The normal subjects in this study did not consistently show this. It is thought that the compliance fall in normals is so small as to be obscured by random measurement errors such as superimposed cardiac pulsations in the esophageal pressure records.

Evidence exists which indicates that in the chronically congested lung a large decrease in lung compliance may be produced by a relatively small increment in pulmonary capillary pressure. Saxton, Rabinowitz, Dexter and Haynes (6) found reversible decreases in compliance to onehalf the resting value in cardiacs on exercise. These large decreases in lung compliance were in some cases associated with pulmonary capillary pressure rises as small as 6 to $10 \mathrm{~mm}$. $\mathrm{Hg}$.

Left for future investigations to explore are the questions :

1. Does a greater increase in pulmonary vascular volume and capillary pressure occur in the cardiac in failure than in the normal on change from the upright to the recumbent?

2. What is the difference between normal and chronically congested lungs with respect to the relationship between vascular pressure and volumes and lung compliance?

The slower changes in compliance which occurred in Patients 5 and 8 when they were studied repeatedly in the supine position may be due to mild degrees of pulmonary edema. It is of interest that in Case 5 a fall in compliance of 50 per cent was associated with no increase of either physical signs or respiratory distress so long as the patient was allowed to lie quietly. Changes in the shape of the volume-pressure curve in this patient indicating extreme stiffness at the beginning of inspiration are similar to observations made in cases of pulmonary edema (5), and suggest its presence. In Case 8, however, volume-pressure curves were linear, changing only their slope but not their shape over the period of supine study. The compliance changes in this case may be on the basis of a gradual rise in pulmonary capillary pressure over the period of study. Unfortunately the obvious experiment of returning these patients to the sitting position and ascertaining the time necessary for compliance to return to the former sitting level was not done.

The curvilinearity of inspiratory volume-pressure curves in several of the patients and the observation of increased static hysteresis suggest exclusion of some groups of alveoli at lower lung volumes which inflate only when their opening pressures are exceeded. Whether collapse is at a bronchiolar level which would result in air trapping or whether there is true collapse of alveoli as observed by Radford and McLaughlin (21) cannot be determined on the basis of the data presented.

The relationship of the observations presented to orthopnea deserves a few words. In this re- 
port, the lungs of several orthopneic patients have been observed to become physically stiffer when these patients assumed a horizontal position. This implies rather directly that the work required to ventilate the lungs of these patients was greater in the horizontal than in the upright position. Though one cannot equate increase in respiratory work with an onset of or increase in dyspnea, there is undeniably a relationship between the two, and it is not unreasonable to suspect that the increased ventilatory work which these patients performed had something to do with the dyspnea which they described when they were horizontal. The subjective symptom orthopnea is probably the result of many factors, the exploration of which is beyond the scope of this discussion. The author suggests that the observations reported may be among the more important of these factors.

One final and fundamental point deserves comment relating to the tacit assumption of identity of esophageal and intrapleural pressures. That these pressures are not identical in the supine position has been previously noted $(13,14)$. In heart disease, where the left atrium, pulmonary veins and other structures close to the esophagus are distended, it may be that the esophageal pressure reflects abnormalities in these structures to a greater extent than alterations in the properties of the lung substance proper. Elucidation of this point awaits comparative studies of pleural and esophageal pressures in human disease states including congestive failure.

\section{CONCLUSIONS}

1. In seven patients with frank congestive heart failure lung compliance fell an average of 21.9 per cent when the body position was changed from sitting to prone; in six of the seven cases the decreases were significant at the 5 per cent level. These compliance decreases were rapid and were promptly reversible. In two of these cases repeat study following successful treatment no longer showed this compliance fall. Eight normal subjects similarly studied showed no significant fall in compliance.

2. In three of the seven patients the inspiratory volume-pressure curves of the lung were curvilinear with lower compliance at small inspired volumes. This change became more marked on assuming the prone position. In the remaining four patients the inspiratory volume-pressure curves were linear.

3. "Static" lung volume-pressure hysteresis was increased in pulmonary congestion and appeared to be roughly proportional to the degree of failure. Hysteresis was not significantly different in sitting and prone positions.

4. In two patients with congestive failure progressive decreases in compliance were noted over four hours when these patients were studied lying quietly in the supine position. These changes were absent on a later occasion when failure was no longer present. Furthermore, normal subjects similarly studied showed no change in compliance. In at least one of these cases the occurrence of sub-clinical pulmonary edema may be the explanation of the compliance fall.

5. It is suggested that the acute and chronic changes in lung compliance observed are partially responsible for the phenomenon of orthopnea.

\section{APPENDIX}

Case 1, T.D., a 35 year old white male, had rheumatic heart disease with stenosis of mitral and aortic valves. On the day prior to compliance studies, right and left heart catheterization had revealed a mean left atrial pressure of $27 \mathrm{~mm}$. $\mathrm{Hg}$, a pulmonary artery pressure of $65 / 33$, and gradients of 12 and $70 \mathrm{~mm} . \mathrm{Hg}$, respectively, across the mitral and aortic valves. The cardiac index was $2.5 \mathrm{~L}$. per minute per M. ${ }^{2}$. Right atrial pressure was $10 \mathrm{~mm}$. Hg. Peripheral edema and elevated venous pressure were noted clinically on the day of study.

Case 2, W.F., was a 28 year old white male with rheumatic heart disease and mitral stenosis who had undergone two commissurotomies, both unsuccessful because of extensive valve calcification. On the day of study the venous pressure was above $180 \mathrm{~mm}$. of $\mathrm{H}_{2} \mathrm{O}$ and edema was present to the level of the knees.

Case 3, F.G., was a 46 year old white male with rheumatic heart disease and mitral stenosis who had not improved following a commissurotomy two years before. On the day of study venous pressure was above $180 \mathrm{~mm}$. of $\mathrm{H}_{2} \mathrm{O}$. Peripheral edema was present and the liver was enlarged and tender.

Case 4, C.M., was a 58 year old white male with arteriosclerotic heart disease. On the day of study the venous pressure was $100 \mathrm{~mm}$. of $\mathrm{H}_{2} \mathrm{O}$. Marked edema was present and his weight was 200 pounds. When restudied seven months later the venous pressure was $80 \mathrm{~mm}$. of $\mathrm{H}_{2} \mathrm{O}$ and his weight was 197 pounds. Moderate edema persisted to the level of mid-tibia.

Case 5, J.N., was a 60 year old Negro male with rheumatic heart disease with predominant mitral insufficiency. On the day first studied, venous pressure was $180 \mathrm{~mm}$. 
of $\mathrm{H}_{2} \mathrm{O}$, edema was present to the level of mid-thigh, the liver was enlarged and he weighed 200 pounds. When restudied three weeks later his weight was 155 pounds, venous pressure was normal and edema, absent.

Case 6, W.W., was a 41 year old Negro male with rheumatic heart disease with predominant mitral stenosis. At the time of the first study the venous pressure was clinically elevated, peripheral edema was present, and the liver was enlarged and tender. Cardiac catheterization done one week before the study revealed a mean left atrial pressure of $25 \mathrm{~mm}$. $\mathrm{Hg}$ and a pulmonary artery pressure of $91 / 35$ at rest. When restudied eight months later and seven months following a successful mitral commissurotomy, the venous pressure was normal, no edema was present, and the patient had nearly normal exercise tolerance.

Case 7, T.J., was a 78 year old diabetic woman with arteriosclerotic heart disease. On the day studied the venous pressure was clinically elevated, peripheral edema was present and the liver was enlarged and slightly tender.

Case 8, D.C., was a 77 year old white male with arteriosclerotic heart disease. When first studied the venous pressure was clinically elevated, edema was present to the level of mid-thigh and the liver was enlarged and tender. His weight was 180 pounds. When restudied one week later venous pressure was clinically normal, edema was absent, the liver smaller and the weight 150 pounds. Supine studies only were done on this patient.

Except in Case 2, venous pressure was estimated from the neck veins by the method of Sir Thomas Lewis (22), and where numerical values are given, the reference level is the sternal angle.

\section{ACKNOWLEDGMENTS}

The author is indebted to Drs. David Greene, Hermann Rahn and Jere Mead for their helpful criticisms and suggestions.

\section{REFERENCES}

1. Christie, R. V., and Meakins, J. C. The intrapleural pressure in congestive heart failure and its clinical significance. J. clin. Invest. 1934, 13, 323.

2. Mead, J., Frank, N. R., Lindgren, I., Gaensler, E. A., and Whittenberger, J. L. A technic for the measurement of pulmonary compliance and resistance: Its application to normal patients and patients with mitral stenosis (abstract). Clin. Res. Proc. 1953, 1, 116.

3. Brown, C. C., Jr., Fry, D. L., and Ebert, R. V. The mechanics of pulmonary ventilation in patients with heart disease. Amer. J. Med. 1954, 17, 438.

4. Marshall, R., McIlroy, M. B., and Christie, R. V. The work of breathing in mitral stenosis. Clin. Sci. 1954, 13, 137.

5. Sharp, J. T., Griffith, G. T., Bunnell, I. L., and Greene, D. G. Ventilatory mechanics in pulmonary edema in man. J. clin. Invest. 1958, 37, 111.
6. Saxton, G. A., Jr., Rabinowitz, M., Dexter, L., and Haynes, F. The relationship of pulmonary compliance to pulmonary vascular pressures in patients with heart disease. J. clin. Invest. 1956, 35, 611.

7. Bondurant, S., Hickam, J. B., and Isley, J. K. Pulmonary and circulatory effects of acute pulmonary vascular engorgement in normal subjects. J. clin. Invest. 1957, 36, 59.

8. Mead, J., McIlroy, M. B., Selverstone, N. J., and Kriete, B. C. Measurement of intraesophageal pressure. J. appl. Physiol. 1955, 7, 491.

9. Clements, J. A., Sharp, J. T., and Johnson, R. P. Simplified method for pulmonary resistance (abstract). Fed. Proc. 1958, 17, 26.

10. Ferris, B. G., Jr., and Pollard, D. Effect of shallow and deep breathing on pulmonary compliance (abstract). Fed. Proc. 1958, 17, 46.

11. Mead, J., Lindgren, I., and Gaensler, E. A. The mechanical properties of the lungs in emphysema. J. clin. Invest. 1955, 34, 1005.

12. von Neergaard, J., and Wirz, K. Die messung der Strömungswiderstände in den Atemwegen des Menchen, insbesondere bei Asthma und Emphysem. Z. klin. Med. 1927, 105, 51.

13. Rahn, H. Personal Communication.

14. Pryor, W. W., Hickam, J. B., Sieker, H. O., and Page, E. B. Effect of circulatory changes on the pulmonary compliance of normal subjects and patients with mitral stenosis. Circulation 1957, 15, 721.

15. Mead, J., Whittenberger, J. L., and Radford, E. P., Jr. Surface tension as a factor in pulmonary volume-pressure hysteresis. J. appl. Physiol. 1957, 10, 191.

16. Borst, H. G., Berglund, E., Whittenberger, J. L., Mead, J., McGregor, M., and Collier, C. The effect of pulmonary vascular pressures on the mechanical properties of the lungs of anesthetized dogs. J. clin. Invest. 1957, 36, 1708.

17. Sjöstrand, $T$. The regulation of blood distribution in man. Acta physiol. scand. 1952, 26, 312.

18. Lägerlöf, H., Eliasch, H., Werkö, L., and Berglund, E. Orthostatic changes of pulmonary and peripheral circulation in man; preliminary report, Scand. J. clin. Lab. Invest. 1951, 3, 85.

19. Donald, K. W., Bishop, J. M., Cumming, G., and Wade, O. L. The effect of of nursing positions on the cardiac output in man. Clin. Sci. 1953, 12, 199.

20. Hamilton, W. F., and Morgan, A. B. Mechanism of the postural reduction in vital capacity in relation to orthopnea and storage of blood in the lungs. Amer. J. Physiol. 1932, 99, 526.

21. Radford, E. P., Jr., and McLaughlin, M. Dependence of lung mechanical properties on anatomical relationships within terminal lung units. Fed. Proc. 1956, 15, 147.

22. Lewis, T. Remarks on early signs of cardiac failure of the congestive type. Brit. med. J. 1930, 1, 849. 